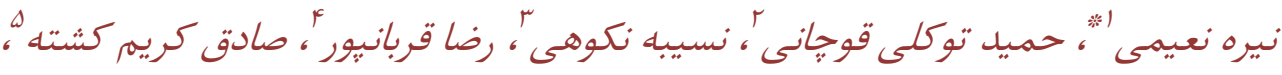

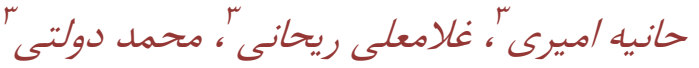

'مربى، عضو هيأت علمى كروه مههندسى بهداشت محيط، دانشكده بهداشت، دانشكاه علوم يزشكى خراسان شمالى، بجنورد، ايران

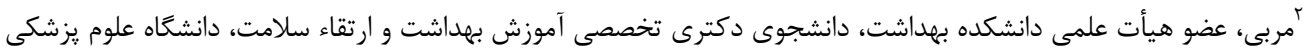

$$
\text { خراسان شمالى، بجنورد، ايران }
$$

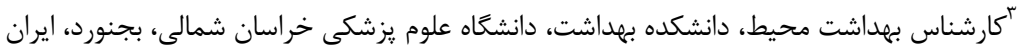

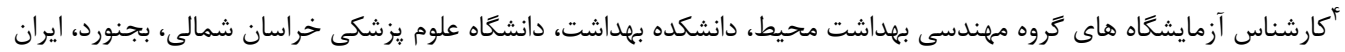

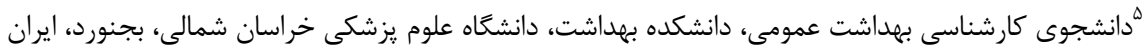

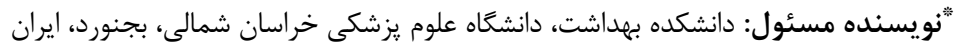
يست الكترونيك: naimi@nkums.ac.ir

حكبيد

زمينه و هدف: علدم مديريت مناسب يسماندهاى بزشكى مخاطرات بهد/شتى، شغلى و زيستمحيطى را بهنبال دارد لذا هدف /ين يزوهش بررسى ميزان كميت و نيز نحوه مديريت بِماندهاى بيمارستانى توليدى در بيمارستانهاى

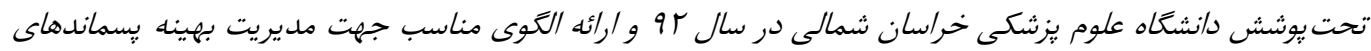
مزبور مىباشد. مواد و روش كار: /ين مطالعهى توصيفى- مقطعى در و بيمارستان تحت يوشش دانشعاه در دو فصل تابستان و

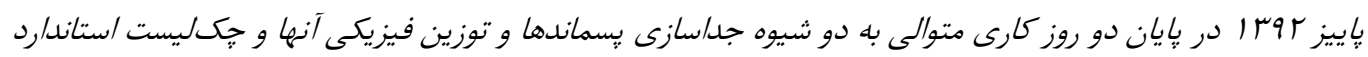

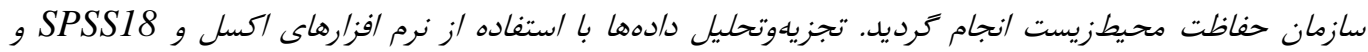

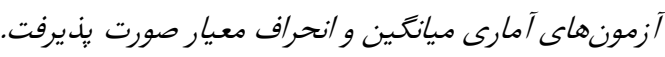

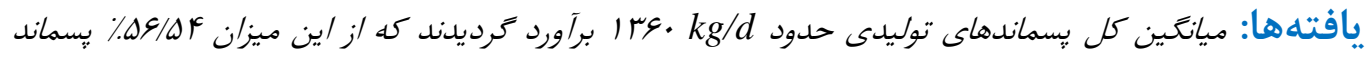

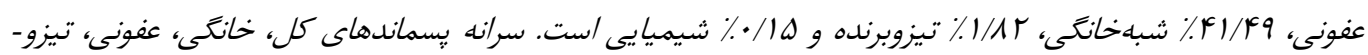
برنده و شيميايى نيز به ترتيب اץ/|

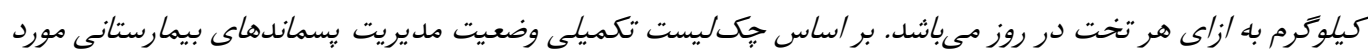

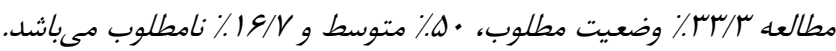
نتيجه كَيرى: طبق نتايج /ين مطالعه ، بيشترين زباله توليدى /ز نوع عفونى است كه در صورت برجسبَّذارى و

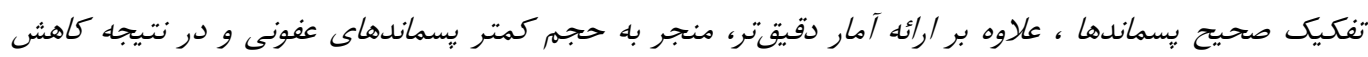

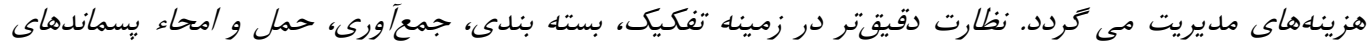

وصول: 9 وص/9/9/1/V: qr/N/IV: اصلاح:

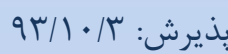

توليدى نيز بيشنسهاد مى شود.

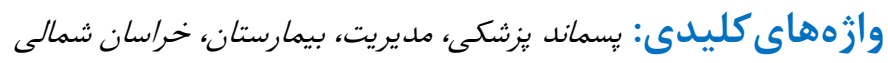




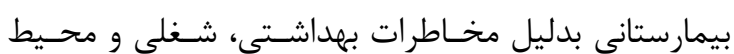

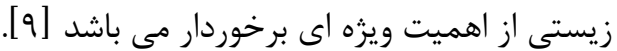

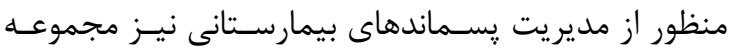

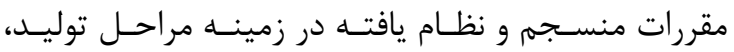

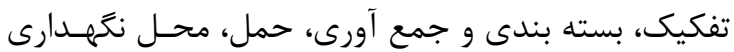
موقت و امحاء پسماند توليدى مى باشد كه مطابق با اصول بهداشت همعانى، حفاظت از منابع، اقتصاد و ساير نيازهاى

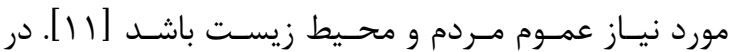
صورت مديريت صحيح يسماندهاى يزشكى، ميـزان توليـد

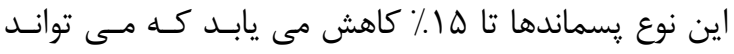

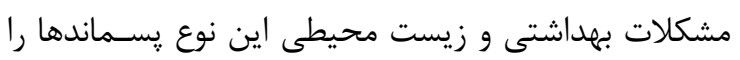

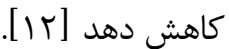

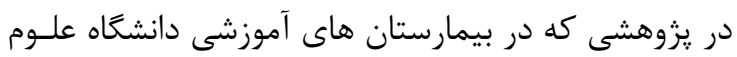

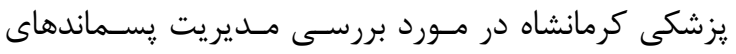

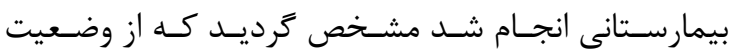

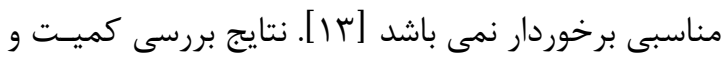

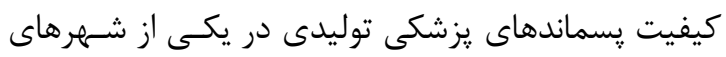

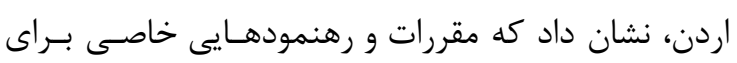

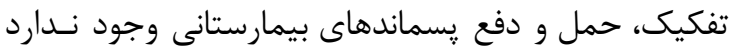

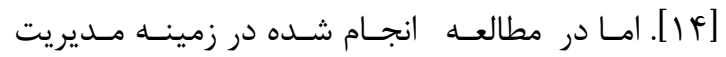

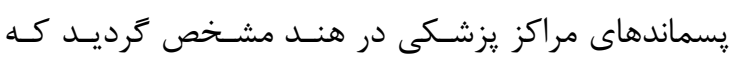

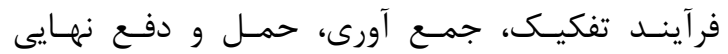

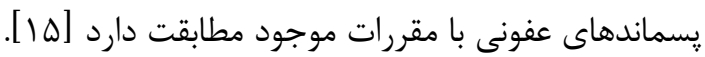
بر اساس كزارش سازمان جهانى بهداشت (999 (199)، ميـزان

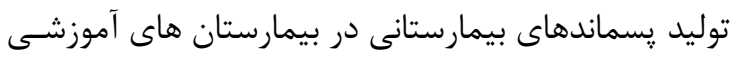

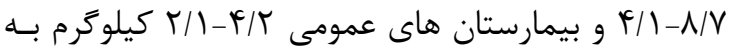

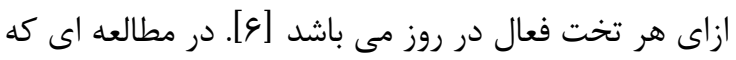

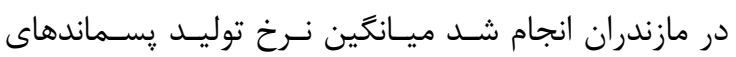

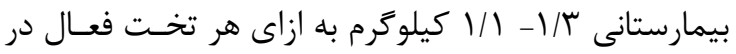

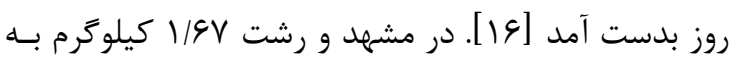

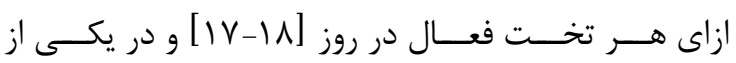

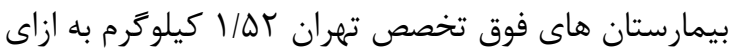

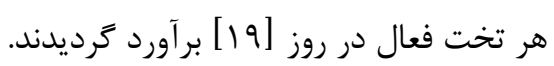

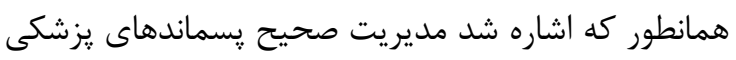

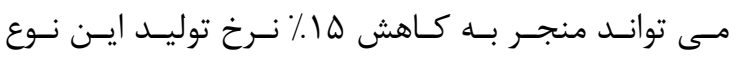

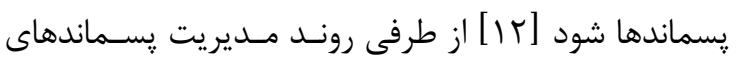

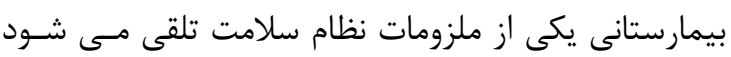

\section{مقلمهه}

كسترش شهرها و رشد سـريع جمعيـت، موجـب افـزايش نيازهاى بهداشتى درمانى و در نتيجـهـ توسعه و گَسـترش

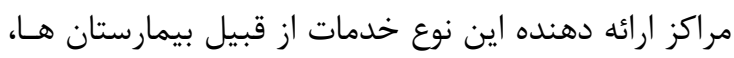

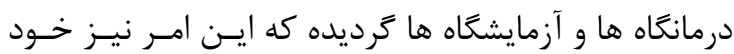

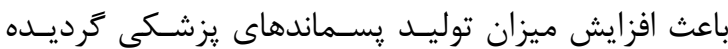

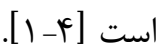

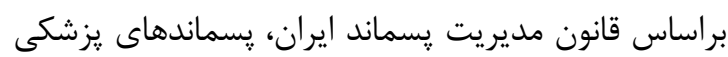
به كليه يسماندهاى عفونى ناشى از بيمارستان ها، مراكز بهداشتى درمانى، آزمايشخاه هاى تشخيص طبسى و سـاير

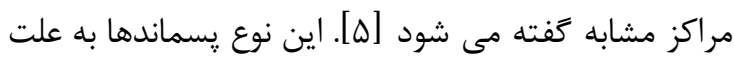

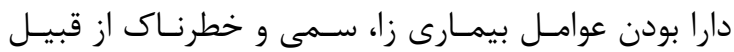
زائدات ياتولوزيك، عفونى، دارويى و شيميايى، راديواكتيو و

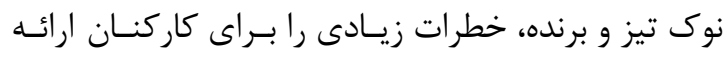

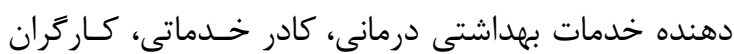

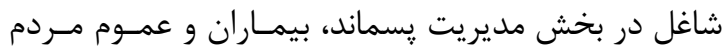
ايجاد مى نمايد [9-9]. در صورت عدم مديريت مناسب يسماندهاى عفونى امكـان

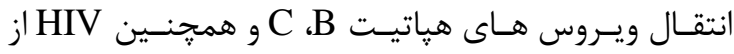

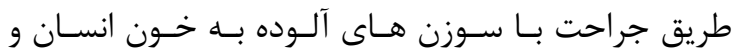

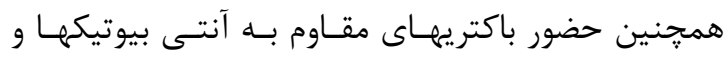

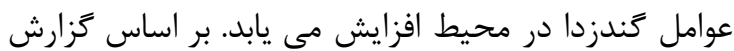

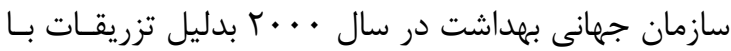

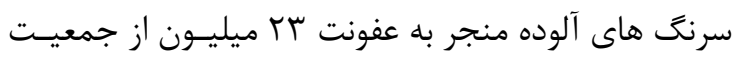

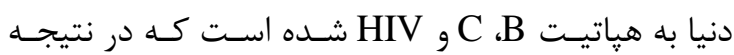

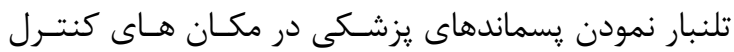

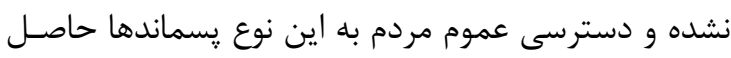

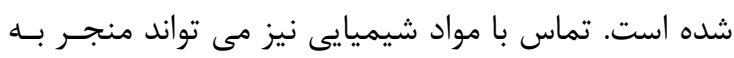
صدمات يوستى، جشمى و غشاء مخاطى دسـتخاه تنفسى

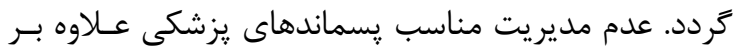

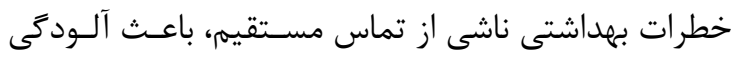

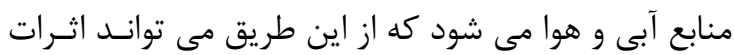

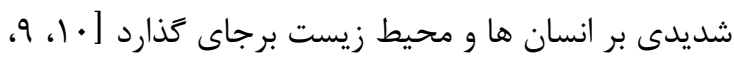

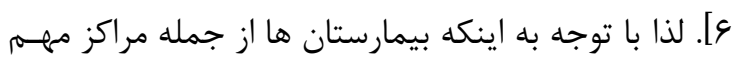

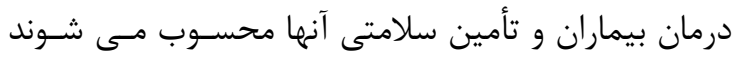

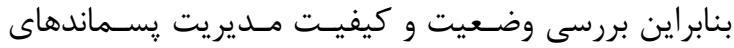


box هاى تهيه شده به همراه برجسب مشخصـات تحويـل

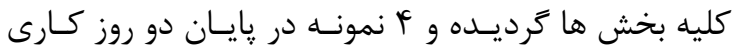
متوالى ميان هفته، يكبار در فصل تابستان و يكبار در فصل

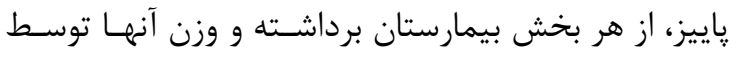

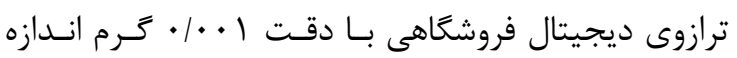
كيرى شد. جهت افزايش دقت كار هر نمونه بَ بـار تـوزين

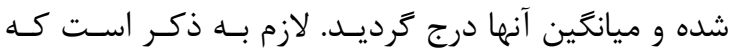

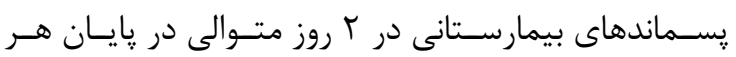
شيفت كارى جمع آورى و بــه ايسـتخاه موقـت يسـماندها منتقل و سيس توزين انجام مى كرديد

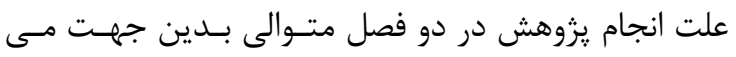

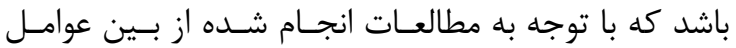

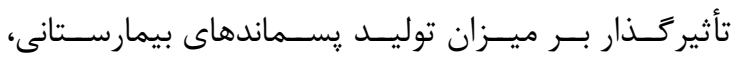

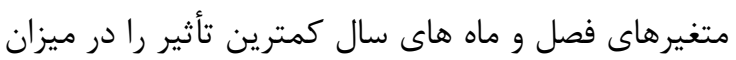

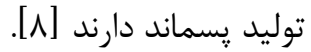
هِ از جمع آورى داده ها، اطلاعات با استفاده از نرم افززار SPSS 18 مورد تجزيه و تحليل قرار كرفتند.

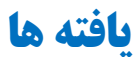

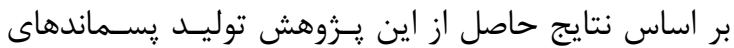

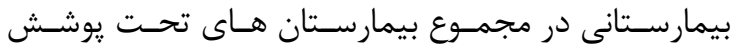

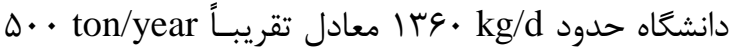
مى باشد كه بيشترين و كمترين پسماند توليدى به ترتيب مربوط به يسماند عفونى و شيميايى مى باشد (نمودار (1).

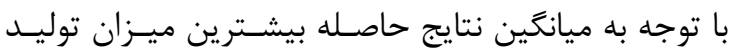

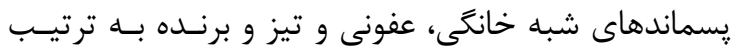

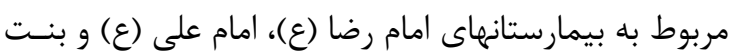

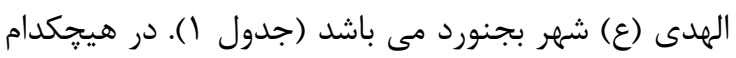
از بيمارستان ها، يسماند پاتولوزيك، راديواكتيو، دارويسى و بهن ظروف فشرده مشاهده نشد. البتـهـ بـا توجـهـ بــه اينكـهـ در

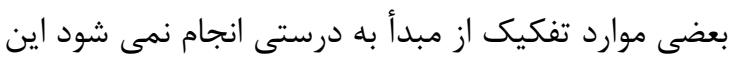

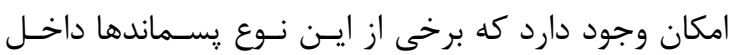

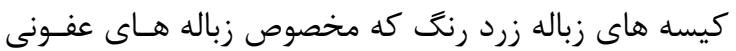

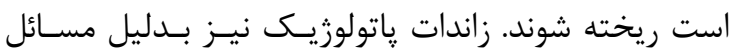

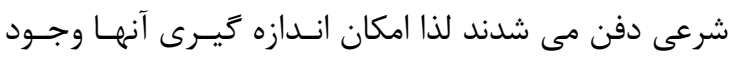

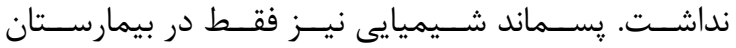
جوادالائمه (ع) جاجرم مشاهده و اندازه كيرى كرديد.

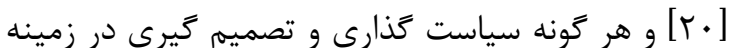
يسماندهاى بيمارستانى نيازمند بررسى وضعيت موجـود از

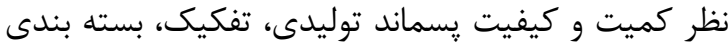

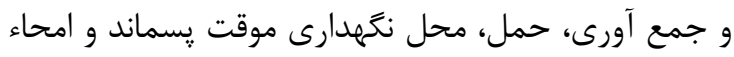

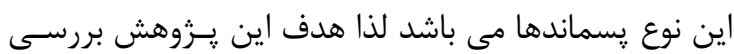

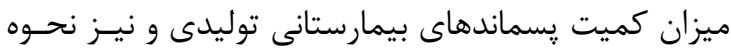

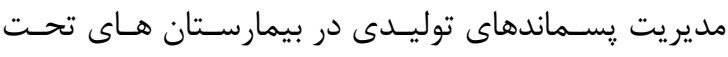

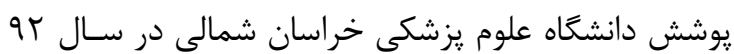
و ارائه الكَوى مناسب جهـت مـديريت بهينـهـ يسـماندهاى

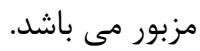

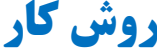

اين مطالعهى توصيفى - مقطعى به منظور بررسى مـديريت

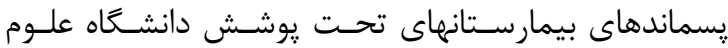

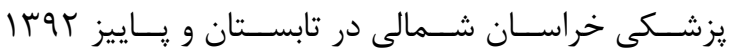

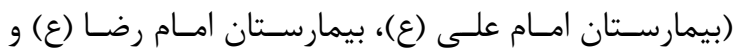

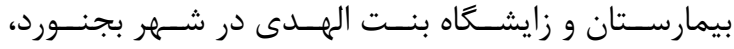

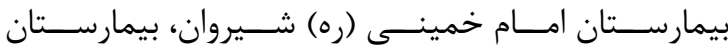

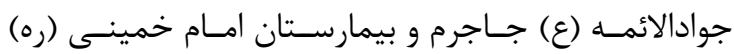

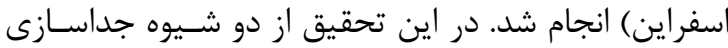

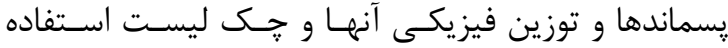

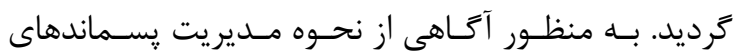

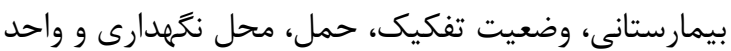
امحاء קِماندها در بيمارستان هاى تحت يوشـش دانشـعاه از جك ليست استاندارد سازمان حفاظت محيط زيست كه دهان

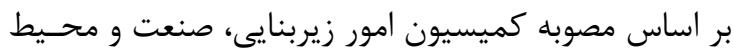

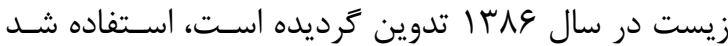

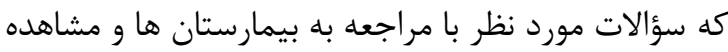

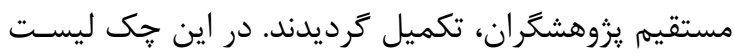

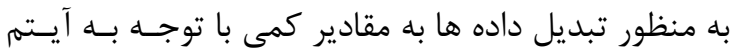
هاى بلى، خير، نياز به اقدام اصلاحى به ترتيب نمـــه با، ل،

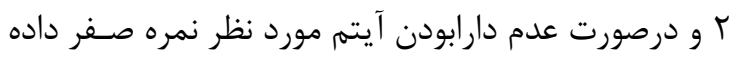

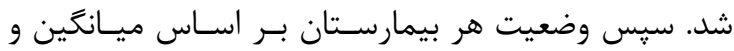

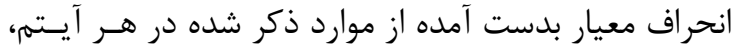

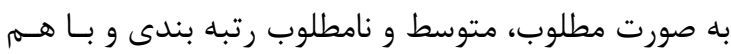

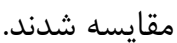
وزن يسماندها نيـز در دو فصـل متـوالى تابسـتان و وـاييز

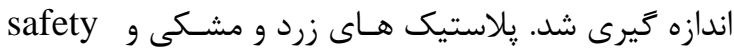




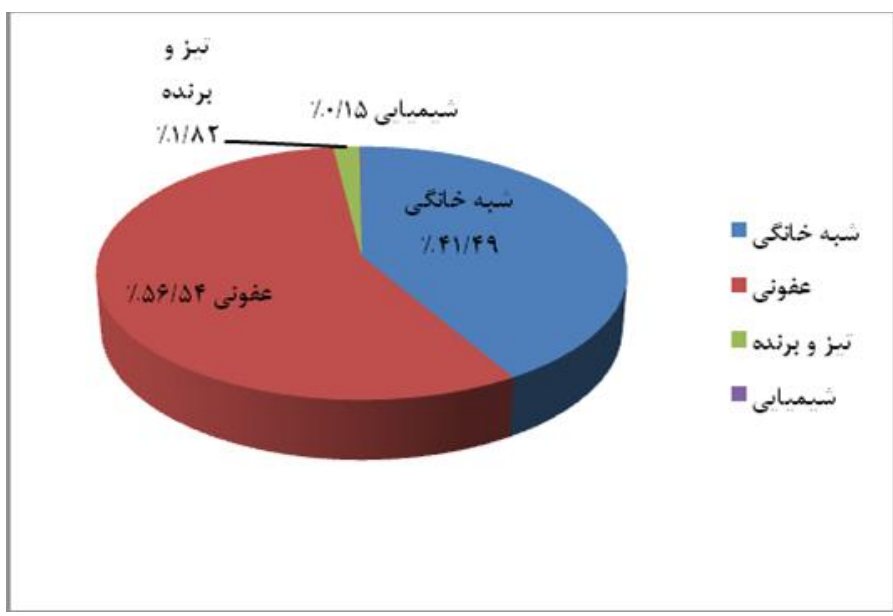

نمودار ا: درصد تركيب وزنى يسماندهاى بيمارستانى توليد شده در

بيمارستان هاى تحت يوشش دانشگاه علوم يزشكى خراسان شمالى

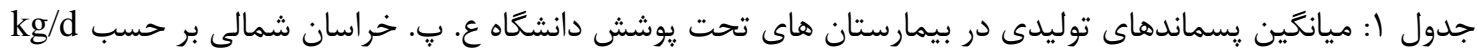

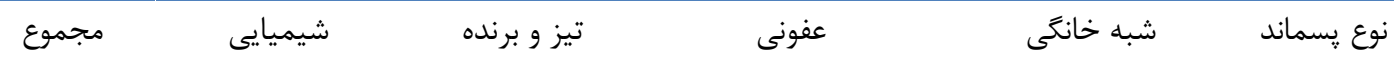

\begin{tabular}{|c|c|c|c|c|c|}
\hline $19 \cdot / 4 \Delta$ & ------------ & $1 / 9 V \pm \cdot / 10$ & $1 \cdots / 9 \Delta \pm r r / r$. & $\wedge \vee / \Lambda \sim \pm \Delta / q$. & امام خمينى (ره) شيروان \\
\hline$I V q / \Delta r$ & -------------- & $9 / 11 \pm \cdot 109$ & $|r F / g| \pm 11 / 9$ & $F \wedge / \Lambda) \pm F / F \wedge$ & امام خمينى (ره) اسفراين \\
\hline $10 \cdot / V 9$ & $r \pm \cdot / \cdots$ & $r / R T \pm \cdot / 1 r$ & $V T / r V \pm r / \Lambda F$ & $V T / V G \pm D / T Y$ & جوادالائمه (ع) جاجرم \\
\hline rqه/r^ & -------------- & $F / M F \pm 1 / \Lambda r$ & $\| \Delta / G T \pm r V / \Delta \mid$ & $\left|V \Delta / \Psi^{q}\right| \pm r \cdot \mid q \Lambda$ & امام رضا (ع) بجنورد \\
\hline ए६q/.q & ------------- & $r / F F \pm r / T \Delta$ & $r|\Lambda /| F \pm r G|\Lambda|$ & $|F V / F \Lambda \pm| r / q \Lambda$ & امام على (ع) بجنورد \\
\hline IVF/TF & -------------- & $G / T \pm r / V M$ & $|r g / F T \pm r| / r \mid$ & $r I / V \pm r / \Lambda V$ & بنت الهدى (ع) بجنورد \\
\hline \multirow[t]{2}{*}{ Irdq/FT } & r & TYMI & VEN/VT & $\Delta 9 r / 9 q$ & مجموع \\
\hline & $\cdot / 11 \pm \cdot 109$ & $F / T F \pm r / \Lambda r$ & $\mid r / \| \pm \Delta \cdot / r \Delta$ & $q \Delta / q r \pm \Delta q / / F$ & ميانگين كل \\
\hline
\end{tabular}

جدول r: ميانگين سرانه يسماندهاى توليدى در بيمارستانهاى تحت يوشش

دانشگاه ع. پ. خراسان شمالى بر حسب kg/bed/day

\begin{tabular}{|c|c|c|c|c|c|c|}
\hline جمع پِماندها & شيميايى & تيز و برنده & 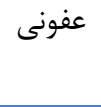 & شبه خانكى & تعداد تخت فعال & بيمارستان \\
\hline$r / \Lambda \cdot 9$ & ------------- & •/.rq & $r / \cdot \| r$ & $I / V \Delta V$ & $\Delta \cdot$ & شيروان \\
\hline I/ATV & --_---------- & $\cdot 1 \cdot 4 q$ & $\cdot / 998$ & $\cdot / 4 q 1$ & Ird & اسفراين \\
\hline F/D९q & .1 .91 & $\cdot / \cdot \Lambda \mu$ & $T / T r$. & $T / T \cdot \Delta$ & سז & جاجرم \\
\hline $1 / T \Delta \varphi$ & ------------- & $\cdot 1 \cdot 11$ & . /4qr & - IVte & tra & امام رضا (ع) بجنورد \\
\hline$r / \Delta \mid$ & --_----------- & ש & I/FAF & r & IfV & امام على (ع) بجنورد \\
\hline t/THE & ------------- & $\cdot 1 \cdot \vee 9$ & $1 / V \& q$ & $\cdot / 4 \cdot 9$ & マ^ & بنت الهدى (ع) بجنورد \\
\hline r/gre & $\cdot 1 \cdot 1$ & $\cdot 1 \cdot 4 q$ & $1 / 494$ & $1 / \wedge \Delta$ & & ميانگين كل \\
\hline
\end{tabular}




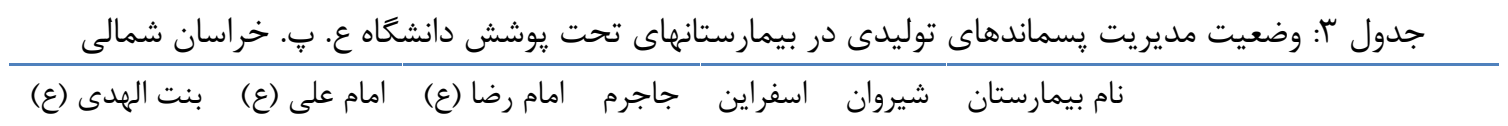

\begin{tabular}{|c|c|c|c|c|c|c|c|}
\hline & $\checkmark$ & $\checkmark$ & $\checkmark$ & $\checkmark$ & & مطلوب & \multirow[t]{3}{*}{ مديريت يسماند } \\
\hline \multirow[t]{2}{*}{$\checkmark$} & & & & & & متوسط & \\
\hline & & & & & $\checkmark$ & 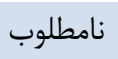 & \\
\hline \multirow[t]{4}{*}{$\checkmark$} & $\checkmark$ & & $\checkmark$ & & $\checkmark$ & 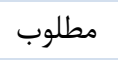 & \multirow[t]{3}{*}{ نيروى انسانى دركير } \\
\hline & & $\checkmark$ & & & & متوسط & \\
\hline & & & & $\checkmark$ & & 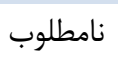 & \\
\hline & $\checkmark$ & & & & & مطلوب & \multirow[t]{3}{*}{ فكيك، بسته بندى و جمع آورى } \\
\hline \multirow[t]{3}{*}{$\checkmark$} & & & $\checkmark$ & $\checkmark$ & $\checkmark$ & متوسط & \\
\hline & & $\checkmark$ & & & & 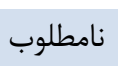 & \\
\hline & $\checkmark$ & & $\checkmark$ & & & 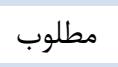 & \multirow[t]{3}{*}{ حمل يسماند } \\
\hline \multirow[t]{3}{*}{$\checkmark$} & & 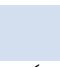 & & $\checkmark$ & $\checkmark$ & متوسط & \\
\hline & & $\checkmark$ & & & & 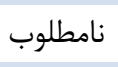 & \\
\hline & $\checkmark$ & & $\checkmark$ & $\checkmark$ & & مطلوب & \multirow[t]{3}{*}{ محل نكَهدارى موقت يسماند } \\
\hline \multirow[t]{4}{*}{$\checkmark$} & & $\checkmark$ & & & & متوسط & \\
\hline & & & & & $\checkmark$ & 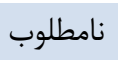 & \\
\hline & & & & $\checkmark$ & & 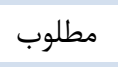 & \multirow[t]{3}{*}{ واحد امحاء پسماند } \\
\hline & $\checkmark$ & $\checkmark$ & $\checkmark$ & & $\checkmark$ & متوسط & \\
\hline$\checkmark$ & & & & & & 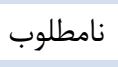 & \\
\hline & $\checkmark$ & $\checkmark$ & $\checkmark$ & & & مطلوب & \multirow[t]{3}{*}{ بارگيرى } \\
\hline$\checkmark$ & & & & & & متوسط & \\
\hline & & & & $\checkmark$ & $\checkmark$ & 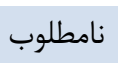 & \\
\hline & $\checkmark$ & & $\checkmark$ & & & 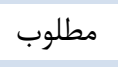 & \multirow[t]{3}{*}{ كل } \\
\hline \multirow[t]{2}{*}{$\checkmark$} & & $\checkmark$ & & $\checkmark$ & & متوسط & \\
\hline & & & & & $\checkmark$ & 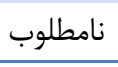 & \\
\hline
\end{tabular}

در . . ا٪ بيمارستان هاى مـورد مطالعـه امكانـات لازم در زمينه تفكيك يسماندهاى يزشكى و شبه خـانكى (كيسـهـ

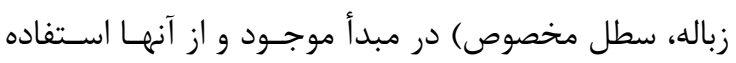

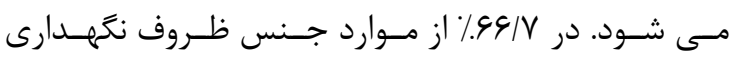

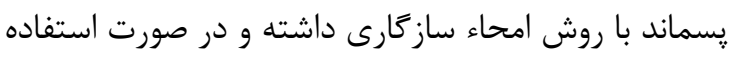

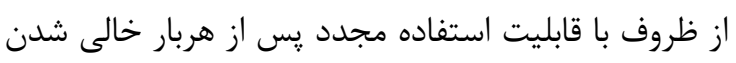

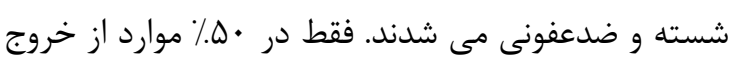

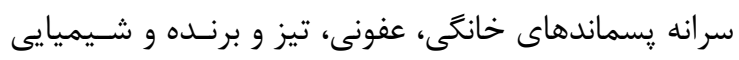
نيز به ترتيب \&

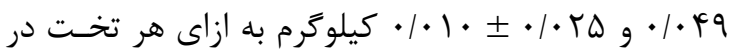
روز مى باشد (جدول r) (؟). در بخش بررسى وضعيت مديريت يسـماند در بيمارسـتان

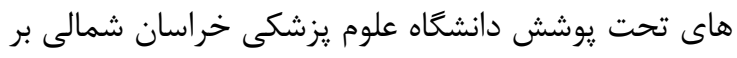
اساس خك ليست تكميلى نتايج زير حاصل ترديد 
دستخاه بصورت هفتتخى و در بقيـهـ مــوارد نيـاز بــه اقـدام

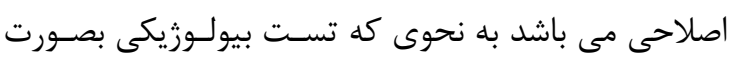

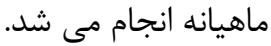

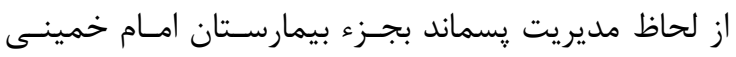

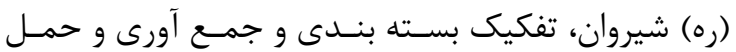

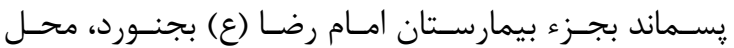

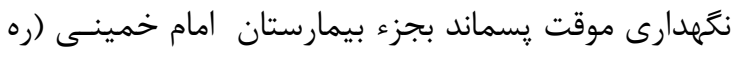

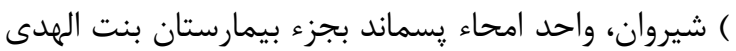
(ع) بجنورد و بارگيرى يسماند بجزء بيمارستان هـاى امـام

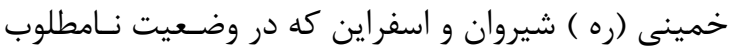

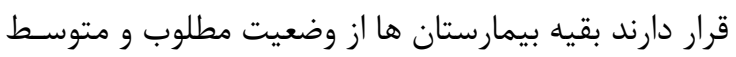
برخوردار مى باشند (جدول بـ).

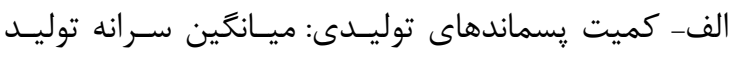

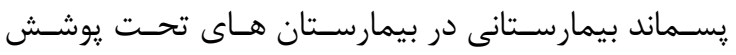

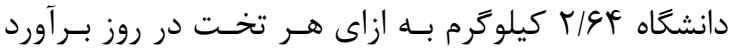

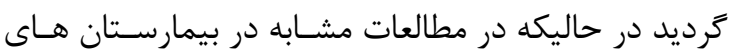

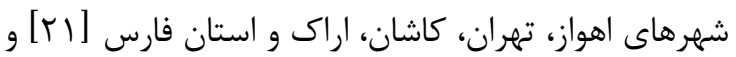

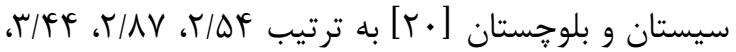

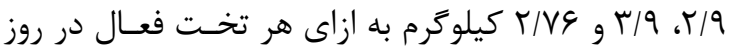
كزارش شده است. سرانه كل توليد پِماندهاى بيمارستان

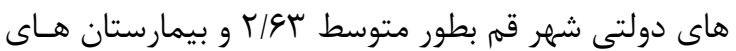

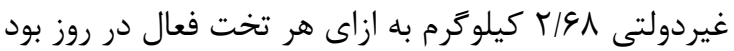

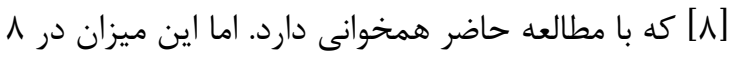
بيمارستان شهر دامانور مصر بطور ميسانخين kg/bed/day

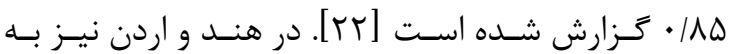

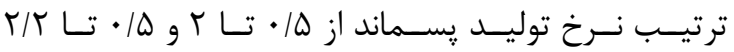

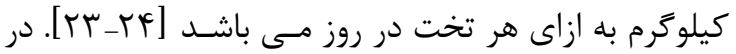

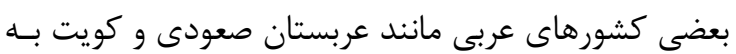

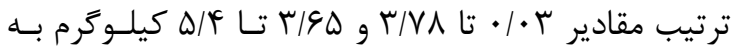

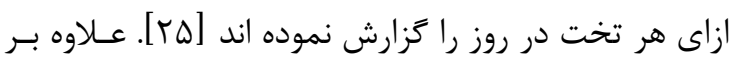

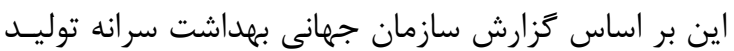

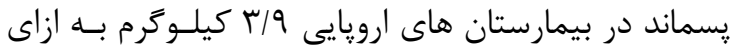

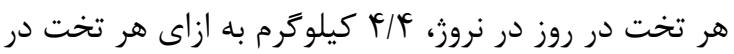

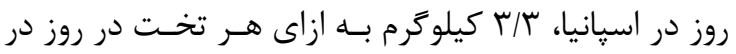
بريتانيا و ه/ ك كيلوگرم به ازاى هر تخت در روز در فرانسـهـ

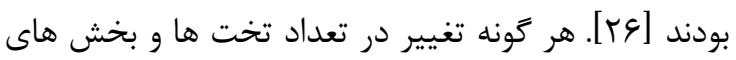

كيسه هاى حاوى يسماند بدون داشتن برجسـب و تعيسين

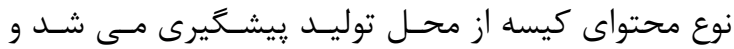
א/ץ"\% از مسؤولان حمل و نقل يسماند از تحويـل گـرفتن

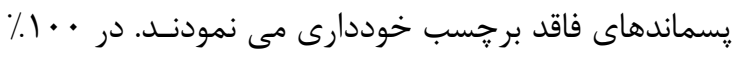

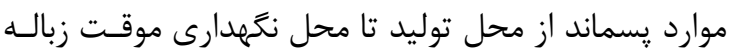
توسط ترولى جرخ دار يا گَارى مخصـوص حمـل يســماند (فاقد لبه هاى تيز و برنده) جابجا مى شدند و جرخ دسـتى مخصوص حمـل يسـماند بـود و بـراى حمـل مــواد ديخـر

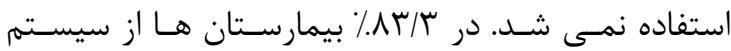
يرتاب براى انتقال زباله به محل نكمهـدارى موقـت يســماند اجتناب مى شد. وضعيت محل نكَهدارى موقت يسماند نيز

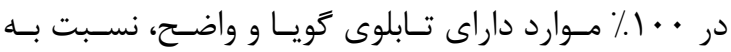

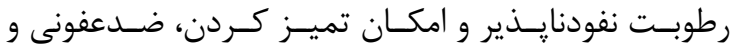

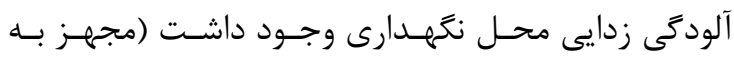
سيستم آب گرم، سرد و كف شوى) و انباردارى : يسـماندها به گَونه اي بود كه از رها شدن ظروف يا كيسه هاى ياره و

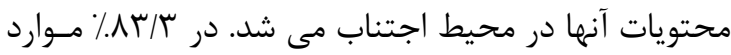

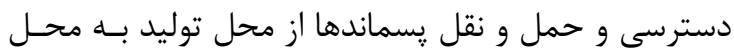

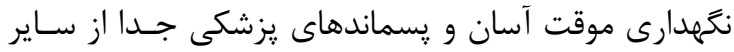

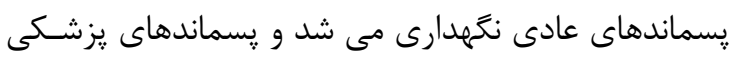

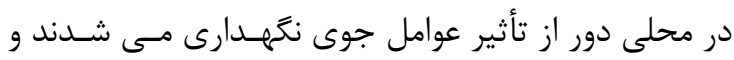

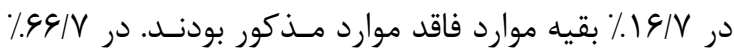

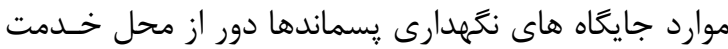

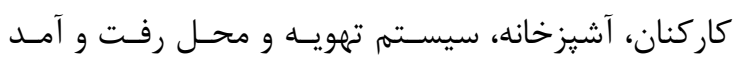

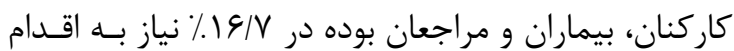

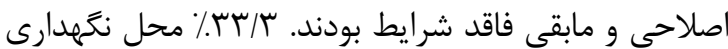
موقت يسماند داراى فضاى كافى نبودند.

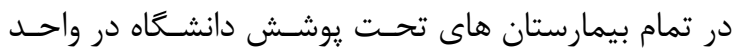

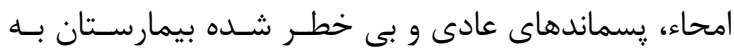
شهردارى تحويل داده مى شـد. محــل مناسـب بـا فضــاى كافى جهت بـى خطرسـازى يسـماندهاى عفـونى و تيـز و و

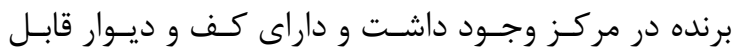

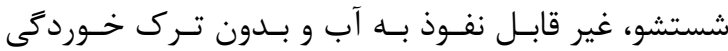

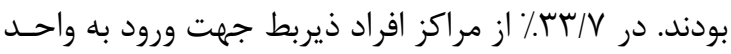
امحاء از كفش يا دميايى مخصوص استفاده نمى كردند. فقط در • •ه. از مراكز تست شيميايى عملكرد دسـتخاه بـهـ

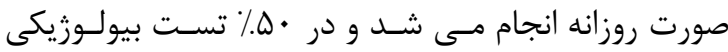


بـ مديريت يسماندهاى بيمارستانى توليدى: با توجـهـ بــهـ

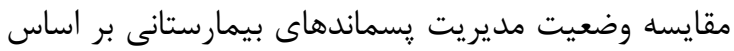
جك ليست تكميلى و با توجه به ميانكين و انحراف معيسار

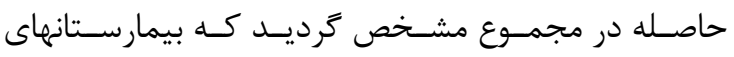

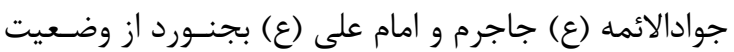

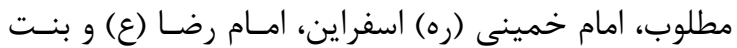

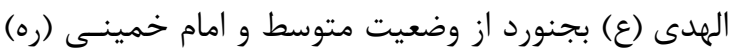

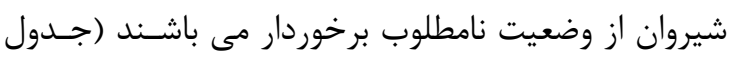

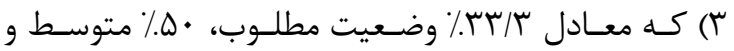

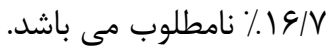

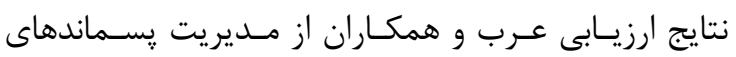

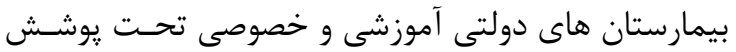

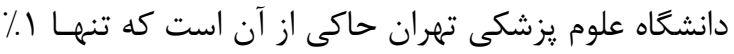

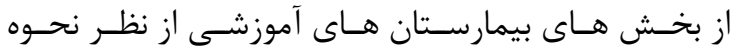

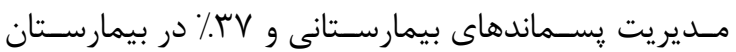

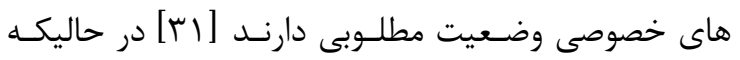

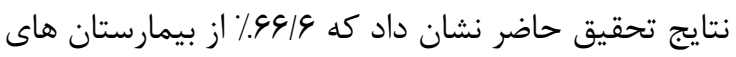

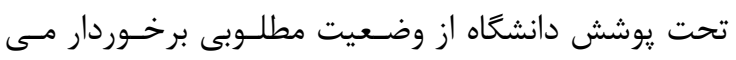
نتايج مطالعه در برزيل حاكى از آن است كه تفكيك، بسته

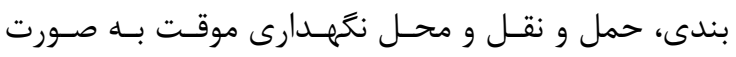

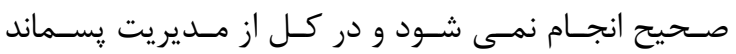

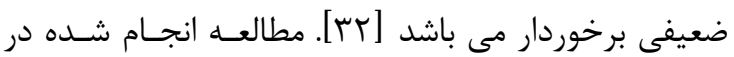

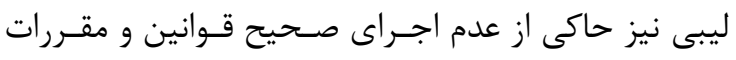

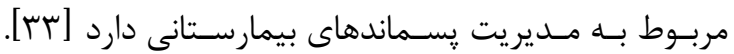
مطالعه ديغرى كه در سال 1991 در 9" بيمارستان تايلند انجام شد بيانكر مديريت نامناسب در كليه بيمارستان هاى داى دائ

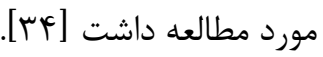

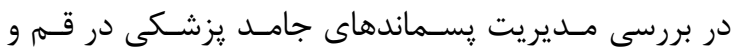

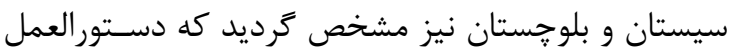

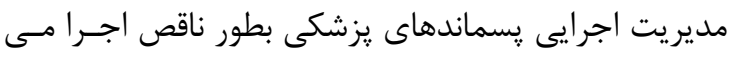

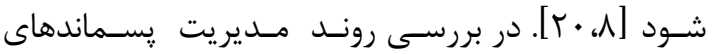
بيمارستانى در سطح بيمارستان هاى خصوصى شهر تهران

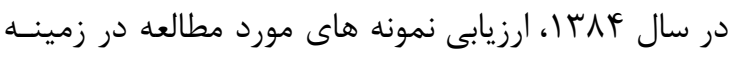

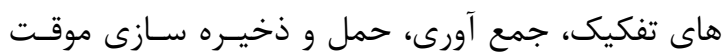

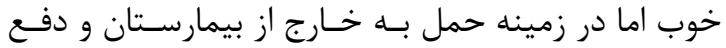

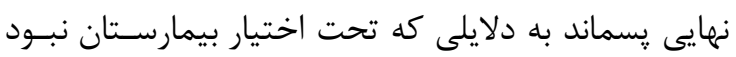

بيمارستان، احتمال تغيير در نرخ توليد يسماند را به همراه

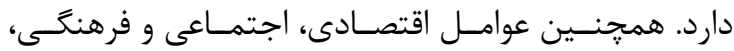

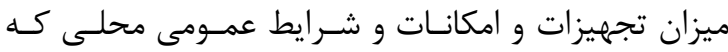

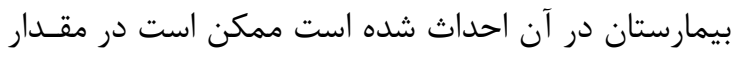
يسماند توليدى تأثير كذار باشد [TV]

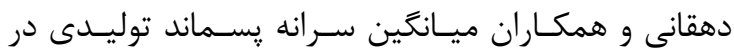

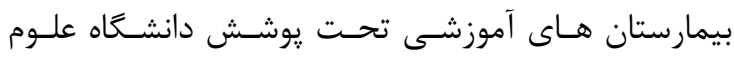

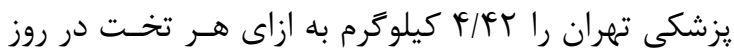

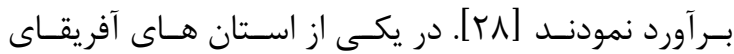
جنوبى ميانكين درصد تركيب پرّماند بيمارسـتانى شـامل

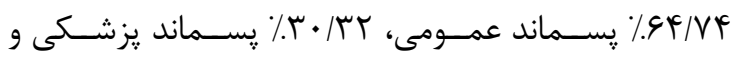

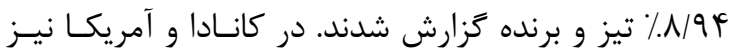

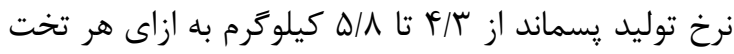

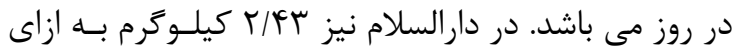

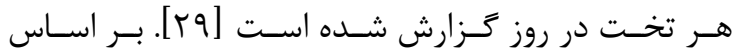
مطالعات انجام شده در ساير كشورهاى جهان حدود • •ا تا

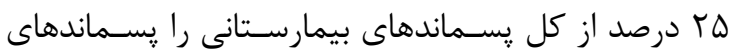

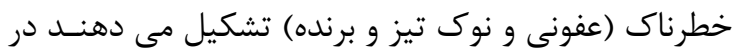

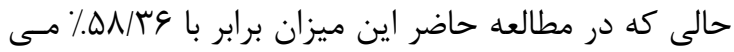

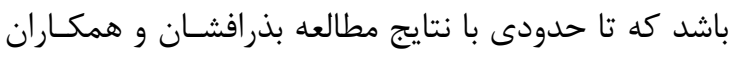
[ [ [ ] همخوانى دارد اما بيشتر از نتايج دهقانى و همكـاران

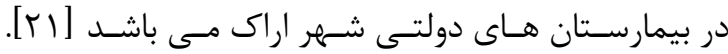
افزايش درصد يسماندهاى خطرناك مى تواند به دليل نوع

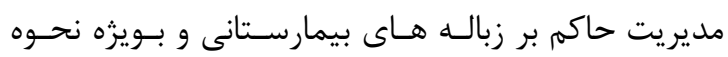

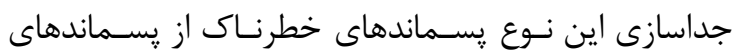

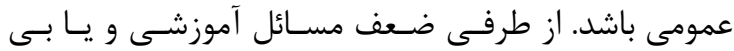
توجهى از طريق دفع يسماندهاى غيرعفونى در كيسه هاى

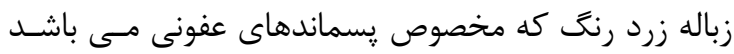

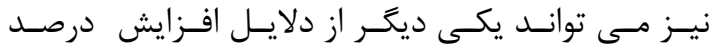
يسماندهاى عفونى نسبت به كل يسماندهاى توليدى شده

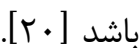
براساس كزارش سازمان جهانى بهداشـت (1999 ) حسدود

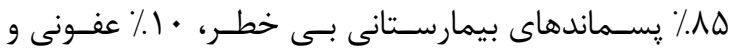

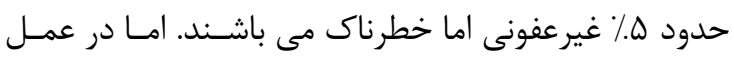

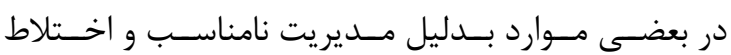

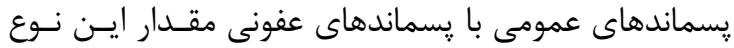

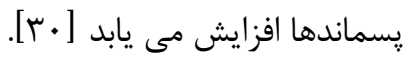




\section{نتيجه تيرى}

به منظور ارتقـاء و بهبـود وضـعيت مـديريت يسـماندهاى

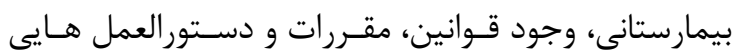

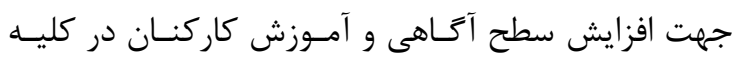

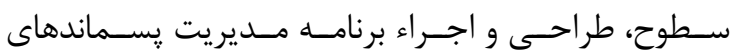

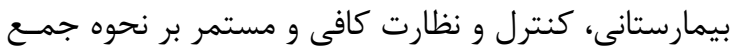

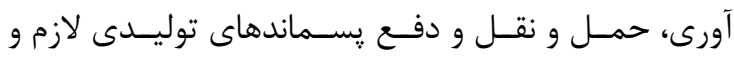

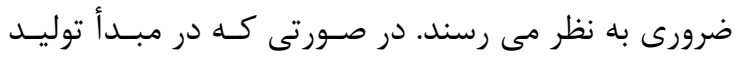

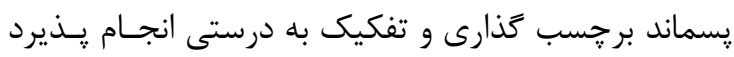

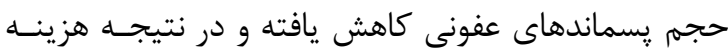
مديريت آنها تقليل مى يابد.

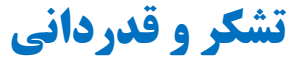

يثروهش حاضر حاصل طرح تحقيقاتى مصـوب بــه شـماره

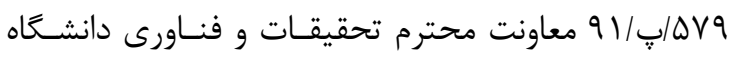

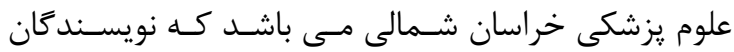

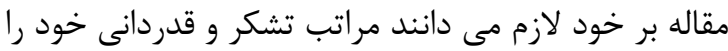

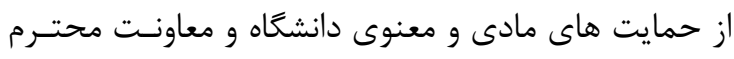
درمان، بيمارستان هاى تابعه دانشخاه و كارشناسان محترم

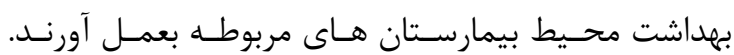




\section{References}

1. Centers for Disease Control and prevention, Healthcare Infection Control practices Advisory Committee (HICPAC), Draft Guideline for Environmental Infection Control in Healthcare Facilities, 2001; 96: 101.

2. Tchobanoglous $G$, Theisen $H$, Integrated Solid waste management, engineering principles and management issues, Mc Graw Hill Pub.1996: 39-67.

3. Omrani GhA, Alavi nakhjavani N, Solid Waste (1): Hospital waste, Andishe raffia Inc., Tehran 2007 [Persian].

4. Sadeghi H, Fazlzadeh M, Hazrati S, Alighadri M, Mokhtari A, Habibzadeh S, Survey of Waste Management Practices at Health Centers of Ardebil City, Health \& Hygiene of Ardebil J., 2011; 2(4): 18-28 [Persian].

5. Department of Environment I.R.Iran. Waste Management Act. Department of Environment Publications. 2004: 1-2.

6. A guide to training materials for health care waste management, I.R. of IRAN ministry of health and medical education environmental health and occupational health center and Tehran university of medical sciences institute for environmental research, 2012 [Persian].

7. Chaerul M, Tanaka M, Shekdar A. A system dynamics approach for hospital waste management, Waste Management, 2008; 28: 442-9.

8. Joneidi A., Jafaripoor MR, Farzadkia M, Hospital waste management of Qom city, Journal of School of Public Health and Institute of Public Health Research, 2010; 8(2): 41-53 [Persian].

9. Dehghani MH, Azam K, Changani F, Dehghanifard E, Quantity and quality of medical wastes in hospitals of Tehran University Medical Sciences in year 2006, Hakim Research J., 2008; 11(1): 40-7 [Persian].

10.Philip L. R., Safe management of health-care waste, World Health Organization, 2003.

11.Atari M. The management of solid wastes disposal in Karaj [M.Sc. Thesis].Tehran: Azad University, Science and Research Branch; 1995 [Persian].

12. Alagoz A, Kocasoy G, Determination of the best appropriate management methods for the healthcare wastes in Istanbul, Waste Management, 2008; 28: 1227-35.

13.Karami-Matin B, The study of hospital waste management in Kermanshah teaching hospitals [M.Sc. Thesis]. Tehran: Tehran University of Medical Sciences; 2001 [Persian].

14.Bdour A, Altrabsheh B, Hadadin N, Al-Shareif M, Assessment of medical wastes management practice: a case study of the northern part of Jordan,Waste Management, 2007; 27:746-59.

15.Patil GV, Pokhrel K, Biomedical solid waste management in an Indian hospital: a case study, Waste Management, 2005; 25:592-9.

16.Mohseni A., Evaluation of medical waste collection, transportation and disposal in public and private hospitals in Mazandaran province, J. Mazandaran University of medical sciences, 2001; 11:4552 [Persian].

17.Sadeghi A., Assessment of collection and disposal management of hospital waste in Mashhad city, MS thesis of environmental health engineering of Tehran university of medical sciences, 2001 [Persian].

18.Ashrafi D., Evaluation of medical waste management in Rasht hospitals, MS thesis of environmental health engineering of Tehran university of medical sciences, 2005 [Persian].

19.Masoumbeigy H, Karimi Zarchi AA, Tajik Jamshid, Evaluation of medical waste quantity in a large extra proficiency hospitals of Tehran, medicine of military J., 2006; 9(2): 129-138 [Persian].

20.Bazrafshan E., Kord-Mostafapoor F., Survey of quantity and quality of hospital wastes in Sistan and Balouchestan province (2009-2010), ZJRMS, 2010; 12(1): 26-32 [Persian].

21.Dehghani MH, Fazelinia F, Omrani GhA, Nabizadeh R, Azam K, Investigation of Management Status on Medical Wastes in Public Hospitals of Arak City, Iran, J. Health \& Environment, 2011; 4(1): 93-104 [Persian].

22.Abd El-Salam MM, Hospital waste management in El-Beheira Governorate, Egypt, Environmental Management, 2010; 91: 618-629. 


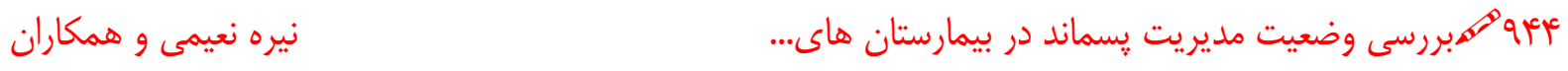

23.Patil AD, Shekdar AV, Health-care waste management in India, Environmental Management, 2001; 63 (2): 211-220.

24.Abdulla F, Abu Qdais H, Rabi A, Site investigation on medical waste management practices in northern Jordan, Waste Management, 2008; 28 (2): 450-58.

25. Franka EA, Health aspects of medical waste management in Tripoli University Hospital (Libya), A Master's thesis, High Institute of Public Health, Alexandria University, Alexandria, Egypt, 2006.

26.WHO, Management of Waste from Hospitals and Health Care Establishments, In: Euro Report and Studies Annexure-III, 97. WHO, Geneva, 1985.

27.Hassan MM, Ahmed SA, Rahman KA, Biswas TK, Pattern of medical waste management: existing scenario in Dhaka City, Bangladesh, 2008, BMC Public Health; 8: 36.

28.Dehghani MH, Azam K, Changani F, Fard DE, Assessment of medical waste management in educational hospitals of Tehran University Medical Sciences, Iranian Journal of Environmental Health Science \& Engineering, 2008; 5 (2): 131-6.

29. Nemathaga F, Maringa S, Chimuka L, Hospital solid waste management practices in Limpopo Province, South Africa: A case study of two hospitals, J. of Waste Management, 2008; 28: 1236-45.

30.Pruss A, Giroult E, Rushbrook P, Safe Management of Wastes from Health-care Activities, WHO: Switzerland, Geneva, 1999.

31.Arab M, Ravangard R, Omrani GhA, Mahmoudi M, Assessment of educational and private hospital waste management in Tehran university of medical sciences, health management J., 2009; 12(38): $71-7$ [Persian].

32.Blenkharn JI. Medical wastes management in the south of Brazil, Waste Management, 2006; 26: 315-7.

33. Sawalem M, Selic E, Herbell JD, Hospital waste management in Libya: A case study, Waste Management, 2009; (29): 1370-75.

34.Danchaivijitrm S, Santiprasitkul S, Tiersuwan S, Naksawas K. Problems in the management of medical waste in Thailand, Journal of the medical association of Thailand, 2005; 88 Suppl 10:S140-4. 35.Rezaei F, Monavari M, Omrani GhA, Assessment of Hospital Waste Management System in Areas of Waste Storage, Collection and Disposal in Private Hospitals of Tehran, Environmental Sciences, 2007; 5(1): 67-80 [Persian]. 


\title{
Assessment of medical waste management in hospitals of North Khorasan university of medical sciences
}

\author{
Naimi $N^{l}$, Tavakoli Ghochani $H^{2}$, Nekohi $N^{3}$, Ghorbanpour $R^{4}$, Karimkoshte $S^{5}$, Amiri $H^{3}$, \\ Reyhani $G h A^{3}$, Dolati $M^{3}$
}

${ }^{1}$ Faculty member of Environmental Health Engineering group, School of Public Health,
North Khorasan University of Medical Sciences, Bojnurd, Iran
${ }^{2}$ Faculty member of Public Health group, School of Public Health, Ph.D student of
Health Education and Health Promotion, North Khorasan University of Medical Sciences,
Bojnurd, Iran
${ }^{3}$ B.Sc of Environmental Health Engineering, School of Public Health, North Khorasan
University of Medical Sciences, Bojnurd, Iran
${ }^{4}$ Laboratory Technologist of Environmental Health Engineering group, School of Public
Health, North Khorasan University of Medical Sciences, Bojnurd, Iran
${ }^{5}$ Student of Public Health group, School of Public Health, North Khorasan University of
Medical Sciences, Bojnurd, Iran
*Corresponding Author: School of Public Health, North Khorasan University of Medical
Sciences, Bojnurd, Iran
Email: naimi@ @ nums.ac.ir

Abstract

Background \& objectives: Inattention to management of medical wastes has environmental, occupational and public health hazards. Therefore this study aimed to determine the amount of hospital waste generated and status of waste management in hospitals of North Khorasan University of Medical Sciences in 2013 and to give a suitable framework for improving waste management practices.

Materials and Methods: This descriptive-cross sectional study was performed in 6 active hospitals of North Khorasan University of Medical Sciences. Sampling was achieved in summer and autumn 2013 for 2 days in each season and by means of laboratory scale were measured. Data were collected using a checklist of environmental health protection of IRAN and for data analysis, SPSS18 (mean $\pm S D$ ) and Excel software were used.

Results: The average of total quantity of waste produced in all hospitals was about $1360 \mathrm{~kg} /$ day comprised of $56.54 \%$ of infectious waste, $41.49 \%$ general waste, $1.82 \%$ sharps waste and $0.15 \%$ chemical waste. Medical waste generation rate for total, general, infectious, sharp and chemical wastes were 2.64 $\pm 1.31,1.085 \pm 0.74$, $1.493 \pm 0.65,0.049 \pm 0.028$ and $0.010 \pm 0.025 \mathrm{~kg} / \mathrm{bed}$-day, respectively. According to completed checklist of hospital waste management, $33.3 \%$ of studied hospitals were favorite, $50 \%$ tolerable and $16.7 \%$ unfavorable.

Conclusion: According to this study, infectious wastes are the most generated waste. In order to reduce the amount of them, action should be taken to deal with pollutants at their source of generation and labeling, which could reduce the costs of hospital waste management and giving more accurate statistics. Effective segregation at the source, appropriate collection methods, safe storage and transportation of waste and control of waste disposal are recommended.

Key words: Medical waste, management, hospital, North Khorasan 